\title{
AN ARTIFICIAL NEURAL NETWORK DESIGN FOR DETERMINATION OF HASHIMOTO'S THYROIDITIS SUB-GROUPS
}

\author{
Mehmet Emin Aktan'1, Erhan Akdoğan², Namık Zengin³, \\ Ömer Faruk Güney ${ }^{4}$, Rabia Edibe Parlar ${ }^{5}$
}

\begin{abstract}
In this study, an artificial neural network was developed for estimating Hashimoto's Thyroiditis subgroups. Medical analysis and measurements from 75 patients were used to determine the parameters most effective on disease sub-groups. The study used statistical analyses and an artificial neural network that was trained by the determined parameters. The neural network had four inputs: thyroid stimulating hormone, free thyroxine (fT4), right lobe size (RLS), and $\mathrm{RLS}^{2}-\mathrm{fT} 4^{4}$, and two outputs for three groups: euthyroid, subclinical, and clinical. After training, the network was tested with data collected from 30 patients. Results show that, overall, the neural network estimated the sub-groups with $90 \%$ accuracy. Hence, the study showed that determination of Hashimoto's Thyroiditis sub-groups can be made via designed artificial neural network.
\end{abstract}

UDC Classification: 004.8, DOI: http://dx.doi.org/10.12955/cbup.v4.845

Keywords: artificial neural networks, hashimoto, thyroiditis, statistical analyze, diagnosis.

\section{Introduction}

Hashimoto's thyroiditis (HT), one of the most common autoimmune disease, was described over a century ago as a pronounced lymphoid goiter affecting approximately $2 \%$ of the population and being 20 times more prevalent in women than men. An autoimmune disease is a disorder in which the body's immune system attacks the body's own cells and organs. Normally, the immune system protects the body from infection by identifying and destroying bacteria, viruses, and other potentially harmful foreign substances. In HT, the immune system attacks the thyroid gland, causing inflammation, and hinders the thyroid gland in producing balancing hormones (Omitek, Burda, \& Wojcik, 2013; Caturegli, Remigis, \& Rose, 2014).

Thyroid hormones regulate metabolism and affect almost all organs in the body. Hashimoto's disease often leads to reduced thyroid function, or hypothyroidism. Hypothyroidism is a disorder that occurs when the thyroid fails to make enough thyroid hormone for the body's needs (Ozyılmaz \& Y1ldirım, 2002). The thyroid produces two thyroid hormones, triiodothyronine (T3) and thyroxine (T4). Triiodothyronine is the active hormone and is derived from T4. Thyroid-stimulating hormone (TSH), which is produced by the pituitary gland in the brain, regulates thyroid hormone production (Omitek, Burda, \& Wojcik, 2013; Caturegli, Remigis, \& Rose, 2014; Ozyılmaz \& Y1ldırım, 2002; Health Information, 2016). The diagnosis of HT is based on the indication of excursive antibodies to thyroid antigens and reduced echogenicity on thyroid sonogram in a patient with proper clinical features. Diagnosis begins with a physical exam and medical history. A goiter, nodules, or growths may be found during a physical exam, and symptoms may suggest hypothyroidism. Health care providers will then perform blood tests to confirm the diagnosis. Diagnostic blood tests may include the TSH test, T4 test, and anti-thyroid and anti-body tests, as well as common methods to diagnose HT, including ultrasound and computational-tomography scans (Ozyılmaz \& Y1ldırım, 2002; Health Information, 2016).

Artificial neural networks (ANNs) are widely used in science and technology, with applications in various branches of engineering and medicine. Artificial neural networks have many advantages, such as, flexible modelling structure for large data sets and highly accurate results that supports clinical decision making. Artificial neural networks have been used in diagnosis of many diseases. In Omitek,

\footnotetext{
${ }^{1}$ Mehmet Emin Aktan, Research assistant, Yildiz Technical University, Department of Mechatronics Engineering, Republic of Turkey, meaktan@yildiz.edu.tr

${ }^{2}$ Erhan Akdoğan, Associate Professor, Yildiz Technical University, Department of Mechatronics Engineering, Republic of Turkey, eakdogan@yildiz.edu.tr

${ }^{3}$ Namık Zengin, Research assistant, Yildiz Technical University, Department of Mechatronics Engineering, Republic of Turkey, zengin@yildiz.edu.tr

${ }^{4}$ Ömer Faruk Güney, Research assistant, Yildiz Technical University, Department of Mechatronics Engineering, Republic of Turkey, oguney@yildiz.edu.tr

${ }^{5}$ Rabia Edibe Parlar, Student, Medipol University, Department of Pharmacy, Republic of Turkey, reparlar@std.medipol.com
} 
Burda, and Wojcik (2013), diagnosis of Hashimoto's thyroiditis was carried out using ultrasound images of thyroid glands and ANN. In Caturegli, Remigis, and Rose (2014), determination of thyroid illnesses was carried out via ANN. In Er, Temurtas, and Tanrikulu (2008), diagnosis of tuberculosis was performed by ANN with $95.08 \%$ accuracy. Castanho, Hernandes, De Re, Rautenberg, and Billis (2013) used an expert system for predicting the pathological stage of prostate cancer. In Takahashi, Hayashi, \& Watanabe (2010), diagnosis of schizophrenia was carried out by ANN with $87.90 \%$ accuracy. In Kaya, Aktan, Akdoğan, and Koru (2015), diagnosis of anemia in children was performed using ANN with $90.00 \%$ accuracy.

The aim of this study is to diagnose (determine) Hashimoto's thyroiditis sub-groups via artificial neural networks. There is no exact therapy or medicine for treating the advanced stage of this disease. This study will help diagnosis early stages of the disease. In this way, patients could be monitored with imaging testing much earlier. A vital issue is to increase the effectiveness of treatment, so that diagnosis can be achieved as early as possible.

\section{Data Analysis}

The analyses, performed using SPSS software, identified the designated parameters from a total of eight (body mass index, waist measurement, hip measurement, TSH, fT3, fT4, right lobe size (RLS), or left lobe size) tested and measured in 75 Hashimoto's thyroiditis patients, that affected the disease sub-groups. Mode, mean, median, and table distribution graphs were obtained from univariate analyses. A regression analysis with a post-hoc test was performed to measure the relationship between two or more variables. This approach provided an opportunity to obtain both descriptive and inferential statistics. Calculations were based on 5\% margin of error. Further hypothesis related to whether the data showed effects in the patients. The results of hypothesis testing were considered suitable for modeling. The t-test and chi-squared test were performed to establish the hypothesis. The t-test was performed for the comparison of paired samples and groups, with a variance test performed to examine the difference between groups. Since the data was homogeneously distributed, a Tukey's range test was performed. The results of the regression analysis, an analysis of variation (ANOVA), and coefficient values identified whether the model could be generated and, following this, a correlation analysis was performed.

\section{Training Artificial Neural Networks}

The Neural Network Toolbox of Matlab@ R2013b was used to create, train, and test the artificial neural network. First, training and test data were normalized between -1 and 1 . Then the training and test data along with the output data were assigned to variables. The network training function, TRAINLM, the learning function, LEARNGDM, and the mean squared error as the performance function were used.

Training and test data were transferred as input data, and the output of training data as target data to create the network and this was followed by training of the neural network. The training was achieved by a backpropagation method after setting the network properties and the training parameters. The network was tested with 30 data points collected from patients.

\section{Results and Discussion}

Table 1 shows the results of the t-Test, and Table 2 the results of the regression and ANOVA. According to the results of the coefficients table, obtained after the regression, the most important parameters affecting the disease sub-groups were TSH, fT4, and RLS.

\section{Structure of Artificial Neural Networks}

The network was developed to feed forward multilayer perceptron with a 3-layer structure. For selection of input parameters, various combinations were trialed for best performance. The results showed that the network was able to diagnose the disease with high accuracy. The network structure is shown in Figure 1. As a result of network training with the three parameters identified from the data analysis, i.e., TSH, fT4, and RLS, up to $80 \%$ accuracy was obtained. Because data of euthyroid and subclinical groups were closely related, effective determination could not be achieved. Therefore, various trials were performed with the power of input parameters and best accuracy (90\%) was 
obtained by squaring the value for the right lobe side and subtracting the value for free triiodothyronine to the power of four (equation: $\mathrm{RLS}^{2}-\mathrm{fT}^{4}$ ). The trial results are shown in Table 4.

Table 1: t-Test statistics of data from 75 Hashimoto's thyroiditis patients

\begin{tabular}{|c|c|c|c|c|c|}
\hline Parameters & Sex & $\mathbf{N}$ & Mean & Std. Deviation & Std. Error Mean \\
\hline \multirow{2}{*}{ Waist } & male & 10 & 88.333 & 14.874 & 4.958 \\
& female & 65 & 81.774 & 10.968 & 1.393 \\
\hline \multirow{2}{*}{ Body Mass Index } & male & 10 & 25.760 & 4.805 & 1.519 \\
& female & 65 & 26.006 & 6.008 & 0.751 \\
\hline \multirow{2}{*}{ Hip } & male & 10 & 100.222 & 9.562 & 3.187 \\
& female & 65 & 102.564 & 10.275 & 1.305 \\
\hline \multirow{2}{*}{ TSH } & male & 10 & 45.363 & 58.636 & 18.542 \\
& female & 65 & 13.547 & 23.792 & 2.951 \\
\hline \multirow{2}{*}{ fT4 } & male & 10 & 0.812 & 0.308 & 0.097 \\
& female & 65 & 0.906 & 0.198 & 0.024 \\
\hline \multirow{2}{*}{ fT3 } & male & 10 & 2.677 & 0.992 & 0.330 \\
& female & 65 & 2.928 & 0.376 & 0.049 \\
\hline \multirow{2}{*}{ RLS } & male & 10 & 19.300 & 5.598 & 1.770 \\
& female & 65 & 16.359 & 2.026 & 0.253 \\
\hline \multirow{2}{*}{ LLS } & male & 10 & 50.300 & 6.783 & 2.145 \\
& female & 65 & 47.890 & 6.796 & 0.849 \\
\hline
\end{tabular}

TSH: thyroid-stimulating hormone; fT4: free thyroxine; fT3: free triiodothyronine; RLS: right lobe side; LLS: left lobe side

Source: Authors

Table 2: Regression results for dependent variable, right lobe side, and predictors, thyroidstimulating hormone, free thyroxine, and free triiodothyronine

\begin{tabular}{|c|c|c|c|c|c|c|c|c|}
\hline \multicolumn{9}{|c|}{ Model Summary } \\
\hline Model & $\mathrm{R}$ & R Square & \multicolumn{3}{|c|}{ Adjusted R Square } & \multicolumn{3}{|c|}{ Std. Error of the Estimate } \\
\hline 1 & $0.202^{\mathrm{a}}$ & 0.04 & & & -0.007 & & & 1.92357 \\
\hline \multicolumn{9}{|c|}{ ANOVA } \\
\hline \multicolumn{2}{|l|}{ Model } & \multicolumn{2}{|c|}{ Sum of Squares } & $\mathrm{df}$ & \multicolumn{2}{|c|}{ Mean Square } & $\mathrm{F}$ & Sig. \\
\hline \multirow[t]{3}{*}{1} & Regression & \multirow{3}{*}{\multicolumn{2}{|c|}{$\begin{array}{r}9.431 \\
222.006 \\
231.438 \\
\end{array}$}} & & \multirow{3}{*}{\multicolumn{2}{|c|}{$\begin{array}{l}3.144 \\
3.700\end{array}$}} & \multirow[t]{3}{*}{0.850} & \multirow[t]{3}{*}{$0.472^{\mathrm{a}}$} \\
\hline & Residual & & & 6 & & & & \\
\hline & Total & & & 6 & & & & \\
\hline \multicolumn{9}{|c|}{ Coefficients } \\
\hline \multirow[b]{2}{*}{ Model } & & \multicolumn{3}{|c|}{ Unstandardized Coefficients } & \multicolumn{2}{|c|}{$\begin{array}{l}\text { Standardized } \\
\text { Coefficients }\end{array}$} & \multirow[b]{2}{*}{$\mathrm{t}$} & \multirow[b]{2}{*}{ Sig. } \\
\hline & & \begin{tabular}{|c|}
$\mathrm{B}$ \\
\end{tabular} & Std. & Error & Beta & & & \\
\hline \multirow[t]{4}{*}{1} & (Constant) & 16.822 & & 2.309 & \multirow{2}{*}{\multicolumn{2}{|c|}{0.136}} & 7.286 & \multirow{2}{*}{$\begin{array}{l}0.000 \\
0.461 \\
\end{array}$} \\
\hline & TSH & 0.009 & & 0.012 & & & 0.742 & \\
\hline & fT4 & 1.632 & & 1.476 & & 0.187 & 1.106 & 0.273 \\
\hline & fT3 & -0.636 & & 0.779 & & -0.157 & -0.816 & 0.417 \\
\hline
\end{tabular}

a Predictors: (Constant). TSH: thyroid-stimulating hormone; fT4: free thyroxine; fT3: free triiodothyronine

Source: Authors 
Table 3: Tukey homogeneous subclinical sets

\begin{tabular}{|c|c|c|c|c|c|c|}
\hline \multicolumn{4}{|c|}{ Body Mass Index } & \multicolumn{3}{|c|}{ Waist } \\
\hline \multirow[b]{2}{*}{ Group } & \multirow[b]{2}{*}{$\mathbf{N}$} & \multirow{2}{*}{\multicolumn{2}{|c|}{$\frac{\text { Subclinical set for alpha }=0.05}{1}$}} & \multirow[b]{2}{*}{ Group } & \multirow[b]{2}{*}{$\mathbf{N}$} & Subset for alpha $=0.05$ \\
\hline & & & & & & 1 \\
\hline \multirow{2}{*}{$\begin{array}{l}\text { euthyroid } \\
\text { clinical }\end{array}$} & 25 & & 25.172 & euthyroid & 25 & 81.652 \\
\hline & 25 & & 25.556 & clinical & 25 & 83.000 \\
\hline $\begin{array}{l}\text { subclinical } \\
\text { Sig. }\end{array}$ & 25 & & $\begin{array}{r}27.241 \\
0.432\end{array}$ & $\begin{array}{l}\text { subclinical } \\
\text { Sig. }\end{array}$ & 25 & $\begin{array}{r}83.125 \\
0.903\end{array}$ \\
\hline \multicolumn{4}{|c|}{ fT4 } & \multicolumn{3}{|r|}{ Hip } \\
\hline \multirow[b]{2}{*}{ Group } & \multirow[b]{2}{*}{$\mathbf{N}$} & \multicolumn{2}{|c|}{ Subclinical set for alpha $=0.05$} & \multirow[b]{2}{*}{ Group } & \multirow[b]{2}{*}{$\mathbf{N}$} & \multirow{2}{*}{$\frac{\text { Subset for alpha }=0.05}{1}$} \\
\hline & & 1 & 2 & & & \\
\hline $\begin{array}{l}\text { clinical } \\
\text { subclinical }\end{array}$ & $\begin{array}{l}25 \\
25\end{array}$ & 0.737 & 0.918 & $\begin{array}{l}\text { clinical } \\
\text { euthyroid }\end{array}$ & $\begin{array}{l}25 \\
25\end{array}$ & $\begin{array}{l}101.791 \\
102.000\end{array}$ \\
\hline $\begin{array}{l}\text { euthyroid } \\
\text { Sig. }\end{array}$ & 25 & 1.00 & $\begin{array}{l}1.020 \\
0.134\end{array}$ & $\begin{array}{l}\text { subclinical } \\
\text { Sig. }\end{array}$ & 25 & $\begin{array}{r}103.000 \\
0.914\end{array}$ \\
\hline \multicolumn{4}{|c|}{ TSH } & \multicolumn{3}{|r|}{ fT3 } \\
\hline \multirow[b]{2}{*}{ Group } & \multirow[b]{2}{*}{$\mathbf{N}$} & \multicolumn{2}{|c|}{ Subset for alpha $=0.05$} & \multirow[b]{2}{*}{ Group } & \multirow[b]{2}{*}{$\mathbf{N}$} & Subset for alpha $=0.05$ \\
\hline & & 1 & 2 & & & 1 \\
\hline $\begin{array}{l}\text { euthyroid } \\
\text { subclinical }\end{array}$ & $\begin{array}{l}25 \\
25\end{array}$ & $\begin{array}{l}3.202 \\
6.791\end{array}$ & & $\begin{array}{l}\text { clinical } \\
\text { subclinical }\end{array}$ & $\begin{array}{l}25 \\
25\end{array}$ & $\begin{array}{l}2.731 \\
2.950\end{array}$ \\
\hline $\begin{array}{l}\text { clinical } \\
\text { Sig. }\end{array}$ & 25 & 0.883 & $\begin{array}{r}43.374 \\
1.000\end{array}$ & $\begin{array}{l}\text { euthyroid } \\
\text { Sig. }\end{array}$ & 25 & $\begin{array}{l}3.005 \\
0.169\end{array}$ \\
\hline
\end{tabular}

RLS: right lobe side; TSH: thyroid-stimulating hormone; fT4: free thyroxine; fT3: free triiodothyronine

Source: Authors

Table 4: Trial results of training artificial neural networks

\begin{tabular}{|c|c|c|c|c|c|}
\hline \multicolumn{2}{|c|}{ Input Parameters: TSH, fT4, RLS } & \multicolumn{3}{l|}{$\begin{array}{l}\text { Input Parameters: TSH, fT4, RLS, } \\
\text { RLS }^{2}-\mathrm{fT}^{2}\end{array}$} \\
\hline & \multicolumn{2}{|c|}{ Accuracy (\%) } & & \multicolumn{2}{c|}{ Accuracy (\%) } \\
\hline Neurons & TANSIG & LOGSIG & Neurons & TANSIG & LOGSIG \\
\hline 20 & 80 & 73 & 20 & 83 & 70 \\
\hline 50 & 83 & 70 & 50 & 83 & 77 \\
\hline 60 & 83 & 80 & 60 & 83 & 80 \\
\hline 70 & 60 & 70 & 70 & 77 & 70 \\
\hline 80 & 73 & 67 & 80 & 77 & 67 \\
\hline 100 & 70 & 60 & 100 & 70 & 67 \\
\hline
\end{tabular}

\begin{tabular}{|l|l|c|c|c|c|}
\hline \multicolumn{2}{|l|}{$\begin{array}{l}\text { Input Parameters: TSH, fT4, RLS, } \\
\text { RLS }^{2}-\mathrm{fT}^{4}\end{array}$} & \multicolumn{2}{l|}{$\begin{array}{l}\text { Input Parameters: TSH, fT4, RLS, } \\
\text { RLS }^{2}-\mathrm{fT}^{6}\end{array}$} \\
\hline \multicolumn{2}{|c|}{ Accuracy (\%) } & & \multicolumn{2}{c|}{ Accuracy (\%) } \\
\hline Neurons & TANSIG & LOGSIG & Neurons & TANSIG & LOGSIG \\
\hline 20 & 63 & 63 & 20 & 60 & 60 \\
\hline 50 & 86 & 77 & 50 & 80 & 77 \\
\hline
\end{tabular}




\begin{tabular}{|c|c|c|c|c|c|}
\hline 60 & 90 & 83 & 60 & 83 & 80 \\
\hline 70 & 80 & 77 & 70 & 73 & 67 \\
\hline 80 & 80 & 73 & 80 & 70 & 60 \\
\hline 100 & 57 & 70 & 100 & 73 & 60 \\
\hline
\end{tabular}

RLS: right lobe side; TSH: thyroid-stimulating hormone; fT4: free thyroxine; fT3: free triiodothyronine

Source: Authors

Figure 1: Network structure

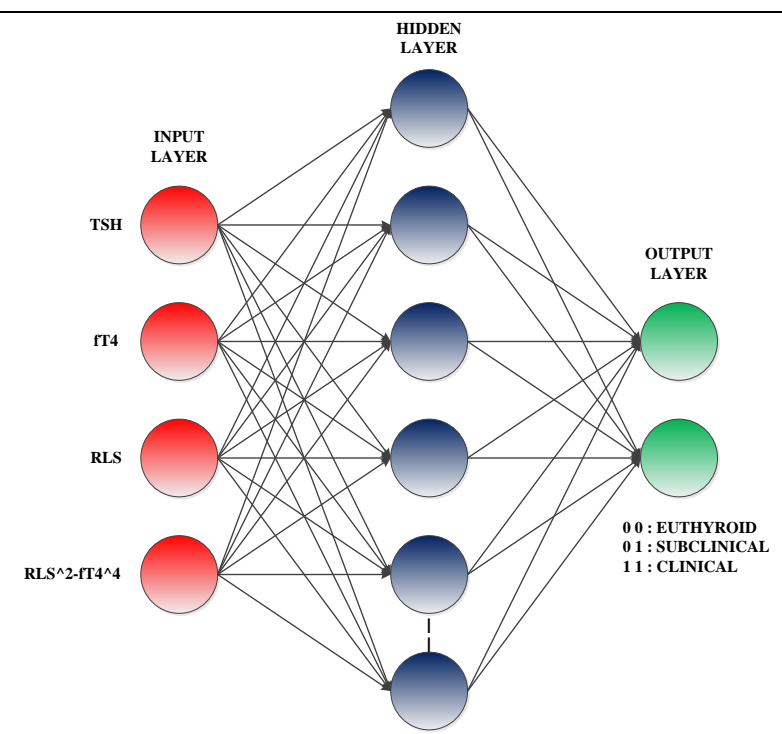

RLS: right lobe side; TSH: thyroid-stimulating hormone; fT4: free thyroxine; fT3: free triiodothyronine

Source: Authors

According to trial results, four of the inputs to the ANN were TSH, fT4, RLS, and $\mathrm{RLS}^{2}-\mathrm{fT}_{4}^{4}$, and two of the outputs were representative of euthyroid, subclinical, and clinical. There were 60 neurons in the hidden layer. Tangent-sigmoid were used as an activation function. The data for 45 of the 75 patients were used for training and another 30 for testing the neural network. Samples of the training and test data are shown in Table 5.

Table 5: Sample training and test data

\begin{tabular}{|c|c|c|c|c|c|}
\hline $\begin{array}{c}\text { TSH } \\
\mathrm{mU} / \mathrm{mL}\end{array}$ & $\begin{array}{c}\text { fT4 } \\
\mathrm{ng} / \mathrm{dL}\end{array}$ & $\begin{array}{c}\text { RLS } \\
\mathrm{mm}\end{array}$ & RLS $^{\mathbf{2}}-\mathbf{f T 4}^{\mathbf{4}}$ & \multicolumn{2}{|c|}{$\begin{array}{c}\text { 0 0: euthyroid } \\
\text { 0 1: subclinical } \\
\mathbf{1} \text { 1: clinical }\end{array}$} \\
\hline 5.80 & 0.91 & 15 & 224.3 & 0 & 1 \\
\hline 20.00 & 0.80 & 12 & 143.5 & 1 & 1 \\
\hline 1.76 & 1.20 & 19 & 358.9 & 0 & 0 \\
\hline
\end{tabular}

RLS: right lobe side; TSH: thyroid-stimulating hormone; fT4: free thyroxine; fT3: free triiodothyronine

Source: Authors

Performance of the network and regression results plots are shown in Figure 2. Figure 2a shows the mean square error (MSE) reached $10^{-23}$ after epoch 600 and best validation performance was $9.0427 \mathrm{e}^{-24}$ at epoch 1000. In contrast, training and validation results were highly satisfactory, depending on the MSE (Figure 2b). This result indicated that the neural network was successfully trained. 
Figure 2: Performance of learning (a) and regression results (b)

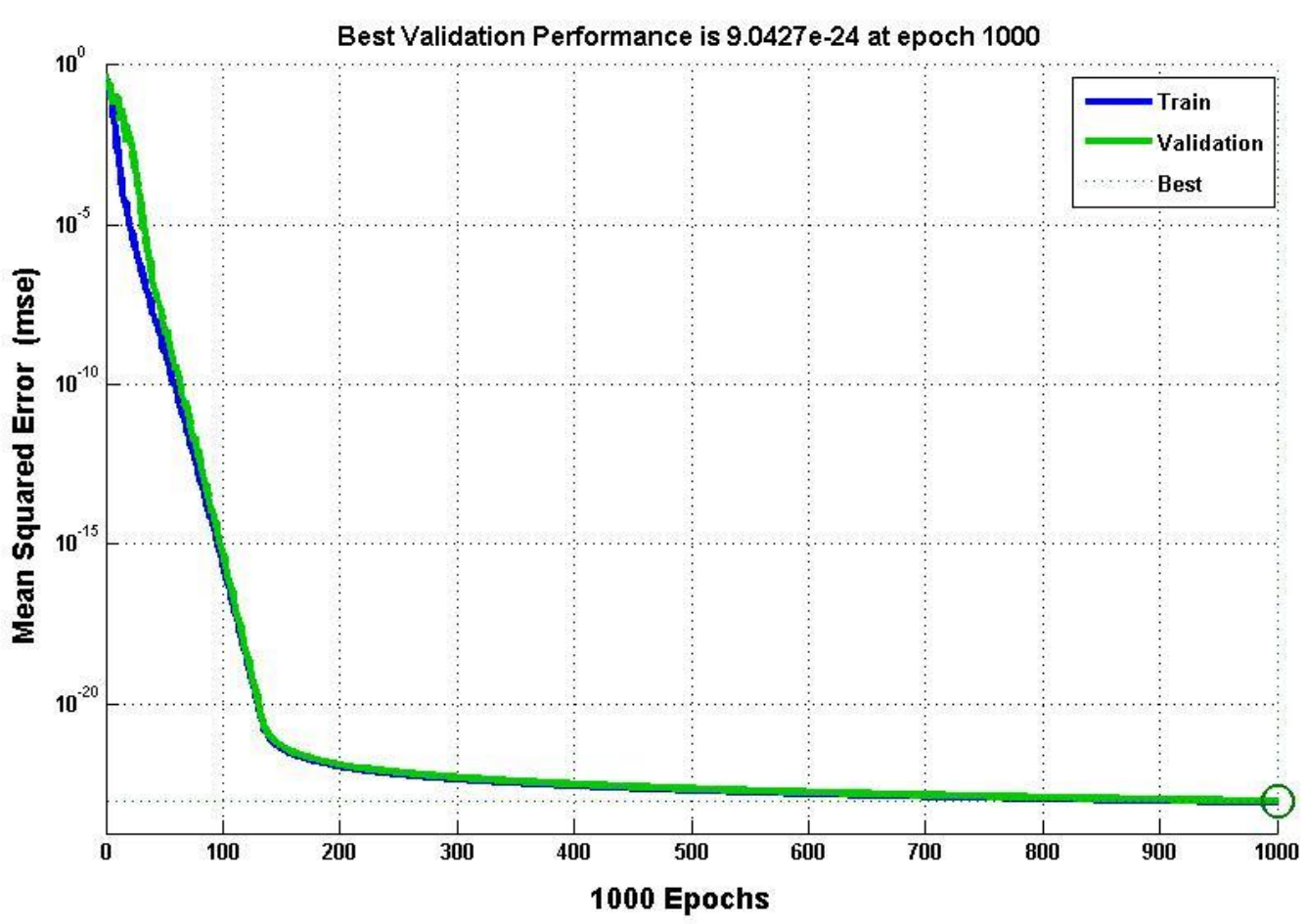

(a)
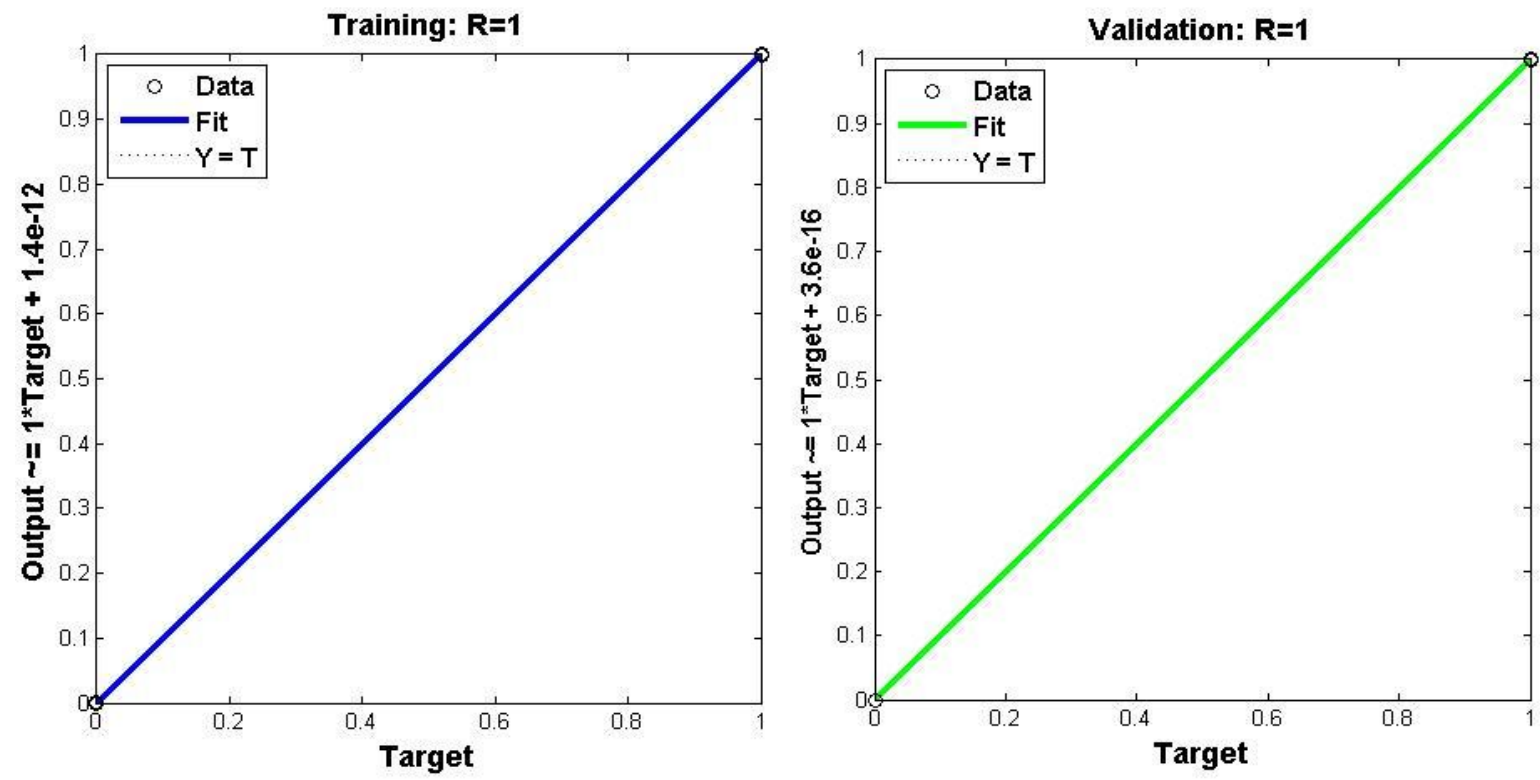

(b)

Source: Authors

Testing Artificial Neural Networks

Once the outputs of the network were compared with actual results, there were three incorrect outcomes found. A comparison of the artificial network outputs with actual doctor's (or 'real') values is shown in Table 4 . The binary numbers ' 0,0 ' indicated the euthyroid sub-group, ' 0,1 ' the subclinical sub-group, and ' 1,1 ' the clinical sub-group. 
Table 4: Test results, comparison of the artificial network outputs with actual (or 'real')

\begin{tabular}{|c|c|c|c|c|c|c|c|c|c|c|c|}
\hline \multirow{2}{*}{$\begin{array}{c}\text { Patient } \\
\text { P1 } \\
\end{array}$} & \multicolumn{2}{|c|}{$\begin{array}{c}\text { Real } \\
\text { Value }\end{array}$} & \multicolumn{2}{|c|}{$\begin{array}{c}\text { Network } \\
\text { Output }\end{array}$} & \multirow{2}{*}{$\begin{array}{c}\begin{array}{c}\text { Accuracy } \\
(\%)\end{array} \\
100 \\
\end{array}$} & \multirow{2}{*}{$\begin{array}{c}\text { Patient } \\
\text { P16 }\end{array}$} & \multicolumn{2}{|c|}{$\begin{array}{c}\text { Real } \\
\text { Value }\end{array}$} & \multicolumn{2}{|c|}{$\begin{array}{c}\text { Networ } \\
\mathbf{k} \\
\text { Output }\end{array}$} & \multirow{2}{*}{$\begin{array}{c}\begin{array}{c}\text { Accuracy } \\
(\%)\end{array} \\
100\end{array}$} \\
\hline & 0 & 0 & 0 & 0 & & & 0 & 1 & 0 & 1 & \\
\hline P2 & 0 & 0 & 0 & 0 & 100 & P17 & 1 & 1 & 1 & 1 & 100 \\
\hline $\mathbf{P 3}$ & 0 & 1 & 0 & 1 & 100 & P18 & 1 & 1 & 1 & 1 & 100 \\
\hline $\mathbf{P 4}$ & 1 & 1 & 1 & 1 & 100 & P19 & 0 & 0 & 0 & 0 & 100 \\
\hline P5 & 1 & 1 & 1 & 1 & 100 & P20 & 0 & 1 & 0 & 1 & 100 \\
\hline P6 & 0 & 1 & 0 & 1 & 100 & P21 & 0 & 0 & 0 & 1 & 0 \\
\hline P7 & 0 & 0 & 0 & 0 & 100 & P22 & 0 & 1 & 0 & 0 & 0 \\
\hline P8 & 0 & 0 & 0 & 0 & 100 & $\mathbf{P 2 3}$ & 1 & 1 & 1 & 1 & 100 \\
\hline P9 & 1 & 1 & 1 & 1 & 100 & P24 & 1 & 1 & 1 & 1 & 100 \\
\hline P10 & 0 & 1 & 0 & 1 & 100 & $\mathbf{P 2 5}$ & 0 & 0 & 0 & 0 & 100 \\
\hline P11 & 0 & 0 & 0 & 0 & 100 & P26 & 0 & 1 & 0 & 1 & 100 \\
\hline P12 & 1 & 1 & 1 & 1 & 100 & P27 & 0 & 0 & 0 & 1 & 0 \\
\hline P13 & 0 & 1 & 0 & 1 & 100 & P28 & 0 & 1 & 0 & 1 & 100 \\
\hline P14 & 1 & 1 & 1 & 1 & 100 & P29 & 0 & 1 & 0 & 1 & 100 \\
\hline P15 & 0 & 0 & 0 & 0 & 100 & P30 & 1 & 1 & 1 & 1 & 100 \\
\hline
\end{tabular}

Source: Authors

For 27 of 30 cases, outputs of the network and decisions of the doctor were in agreeance, and total accuracy of the artificial neural network was $90 \%$ (Table 4). Incorrect predictions emerged in the euthyroid and subclinical groups, while the clinical group was estimated with $100 \%$ accuracy.

\section{Conclusion}

This paper describes an artificial neural network that was developed to determine Hashimoto's thyroiditis sub-groups. Medical analyses and measurements, from 75 patients, were used to determine the most influential parameters on the disease sub-groups. The study used statistical analyses and a neural network that was trained by the determined parameters. In the test, outputs of the network were compared to the decisions of the doctor. The reason for the outcome was that euthyroid and subclinical sub groups were closely related. We consider the developed artificial neural network model adequate for use in helping doctors determine Hashimoto's thyroiditis sub-groups.

\section{Acknowledgement}

We would like to thank Prof. Dr. Handan Ankarali and Dr. Merve Aktan for their support and valuable comments.

\section{References}

Castanho, M. J. P., Hernandes, F., De Re, A. M., Rautenberg, S., \& Billis, A. (2013). Fuzzy expert system for predicting pathological stage of prostate cancer. Expert systems with applications 466-470.

Caturegli, P., Remigis, A., \& Rose, N. R. (2014). Hashimoto thyroiditis: Clinical and diagnostic criteria, Autoimmunity reviews.

Er, O., Temurtas, F., \& Tanrıkulu, A. Ç. (2008). Tuberculosis disease diagnosis using artificial neural networks. Journal of Medical Systems 299-302.

Health Information (2016) www.niddk.nih.gov/health-information/health-topics/endocrine/hashimotos-disease/ 16.03.2016.

Kaya, E., Aktan, M. E., Akdoğan, E., \& Koru, A. T. (2015). Diagnosis of anemia in children via artificial neural network. International Journal of Intelligent Systems and Applications in Engineering, 24-27.

Omitek, Z., Burda, A., \& Wojcik, W. (2013). The use of decision tree induction and artificial neural networks for automatic diagnosis of Hashimoto's disease. Expert Systems with Applications 6684-6689.

Ozyılmaz, L., \& Y1ldırım, T. (2002). Diagnosis of thyroid disease using artificial neural network methods. Proceedings of the 9th International Conference on Neural Information Processing Vol: 4,2033-2036.

Takahashi, M., Hayashi, H., \& Watanabe, Y. (2010). Diagnostic classification of schizophrenia by neural network analysis of blood-based gene expression signatures. Schizophrenia Research 210-218. 